\title{
Analysis of Antarctic proteobacteria by PCR fingerprinting and screening for antimicrobial secondary metabolites
}

L.-H. Lee', Y.-K. Cheah ${ }^{1}$, A.M. Nurul Syakima', M.S. Shiran², Y.-L. Tang ${ }^{3}$, H.-P. Lin $^{3}$ and K. Hong ${ }^{3,4}$

${ }^{1}$ Department of Biomedical Science, Faculty of Medicine and Health Sciences, Universiti Putra Malaysia, Selangor Darul Ehsan, Malaysia

${ }^{2}$ Department of Pathology, Faculty of Medicine and Health Sciences, Universiti Putra Malaysia, Selangor Darul Ehsan, Malaysia

${ }^{3}$ Key Laboratory of Tropical Microbial Resources, Hainan Province, Institute of Tropical Bioscience and Biotechnology,

Chinese Academy of Tropical Agricultural Sciences, Haikou, P.R. China

${ }^{4}$ Key Laboratory of Combinatorial Biosynthesis and Drug Discovery,

Ministry of Education, Wuhan University, School of Pharmaceutical Sciences, Wuhan, P.R. China

Corresponding author: Y.-K. Cheah

E-mail: ykcheah@medic.upm.edu.my

Genet. Mol. Res. 11 (2): 1627-1641 (2012)

Received October 11, 2011

Accepted February 1, 2012

Published June 15, 2012

DOI http://dx.doi.org/10.4238/2012.June.15.12

ABSTRACT. Fifty-seven proteobacterium species were successfully isolated from soils of Barrientos Island of the Antarctic using 11 different isolation media. Analysis of 16S rDNA sequencing of these isolates showed that they belonged to eight different genera, namely Bradyrhizobium, Sphingomonas, Methylobacterium, Caulobacter, Paracoccus, Ralstonia, Rhizobium, and Staphylococcus. All isolates were studied for capability of producing antimicrobial and antifungal secondary metabolites using high-throughput screening models. Approximately 23 (13/57) and 2\% (1/57) of isolates inhibited growth 
of Candida albicans ATCC $10231^{\mathrm{T}}$ and Staphylococcus aureus ATCC $51650^{\mathrm{T}}$, respectively. These results indicated that proteobacterium species isolates from Antarctic could serve as potential source of useful bioactive metabolites. Enterobacterial repetitive intergenic consensus (ERIC)-PCR fingerprinting produced nine clusters and 13 single isolates, with a high D value of 0.9248 . RAPD fingerprinting produced six clusters and 13 single isolates, with a relatively low D value of 0.7776. ERIC-PCR analysis proved to have better discrimination capability than RAPD analysis and generated better clustering for all proteobacterium species isolates. We conclude that ERIC-PCR is a robust, reliable and rapid molecular typing method for discriminating different genera of proteobacteria.

Key words: Diversity; Proteobacteria; High-throughput screening; 16S rRNA; ERIC-PCR; RAPD

\section{INTRODUCTION}

Proteobacteria are a major phylum of bacteria, which are all Gram-negative bacteria. This bacterial taxonomy has been frequently found in Antarctic soils (Aislabie et al., 2008). Soil is an intensively exploited ecological niche that harbors inhabitants, which could produce many useful bioactive natural products, like antibiotic and antifungal compounds (Thakur et al., 2007). Lately the development of antimicrobial resistance among pathogenic bacteria and fungus has become a major health concern worldwide (Dias de Oliveira et al., 2005). The rise of resistant pathogenic bacteria and fungus is driving the need for new antimicrobial drugs, which continue to be of the utmost importance in screening programs globally. For many years, the drugs used successfully to treat various diseases were bacterium-derived compounds (Aislabie et al., 2008). Recently, due to the possible frequent genetic exchange between species (Bredholt et al., 2008), the chances of novel discovery of bioactive molecules from various well-known bacteria seem to have fallen dramatically. For example, the isolation of highly bioactive Streptomyces from different environments still produces similar metabolites or compounds.

The increase in duplicate findings has led to a serious rise in demand for new useful molecular structures in pharmacology industries. Many reports have shown that careful exploration of poorly explored areas and new habitats of the world like the Antarctic, Australia, China, and Jordan could provide novel microorganisms and useful products (Moncheva et al., 2002; Saadoun and Gharaibeh, 2003). Therefore, the exploration of new habitats with poorly explored areas and unusual environments has become critical for the discovery of novel bacteria and metabolites (Lam, 2007; Newman and Cragg, 2007; Thakur et al., 2007).

Poorly explored areas like the Antarctic present significant potential for the discovery of novel microorganisms like bacteria and biological active metabolites (Moncheva et al., 2002; Marinelli et al., 2004; Tindall, 2004; Taton et al., 2006; Bull and Stach, 2007). Barrientos Island is located at $62^{\circ} 24^{\prime} \mathrm{S}, 59^{\circ} 47^{\prime} \mathrm{W}$, at the north entrance to the English Strait between Greenwich and Robert Islands. This island is occupied by various breeders like chinstrap penguins (Pygoscelis antarctica), gentoo penguins (Pygoscelis papua), southern giant petrels (Macronectes giganteus), kelp gulls (Larus dominicanus), and skuas (Catharacta spp). The 
whole centre of the island is covered by a tremendously extensive moss carpet. Lichens Xanthoria spp, Caloplaca spp and other crustose lichen species are present.

The novelty and effectiveness of antimicrobial screening models are important in order to increase the chances of discovering novel metabolites. Therefore, high-throughput screening models were made available to detect antimicrobial activities (Hong et al., 2009). Molecular-based techniques like 16S rRNA analysis were used for molecular identification of isolates, whereas PCR fingerprinting methods like enterobacterial repetitive intergenic consensus (ERIC)-PCR and RAPD were examined for their discriminatory capability in differentiating different genera of proteobacteria. All molecular techniques stated above were used to study the genetic relatedness of bioactive proteobacterium isolates.

The aims of this study were: i) to recognize the distribution of proteobacteria from soils of Barrientos Island using a culturable method; ii) to identify the isolates using 16S rRNA analysis and high-throughput screening models to determine the bioactivity of secondary metabolites; iii) to use ERIC-PCR and RAPD to create a molecular profile of proteobacteria from different genera; iv) to study genetic relatedness of bioactive proteobacteria using 16S rRNA, ERIC-PCR and RAPD.

\section{MATERIAL AND METHODS}

\section{Environmental sampling}

Soil samples of different locations were collected from Barrientos Island during the XI Ecuadorian Antarctic Expedition to Research Station "Pedro Vicente Maldonado", Greenwich Island, and South Shetlands Islands of 2007. The soil samples of the upper 20$\mathrm{cm}$ layer (after removing the top 2-3 cm) were collected from 5 different sites that harbor various interesting fauna and flora activities. Soils were sampled into sterile plastic bags using an aseptic metal trowel, and kept in the dark for transport to Malaysia. Soils were subsequently stored at $-20^{\circ}$ and $-80^{\circ} \mathrm{C}$.

\section{Isolation of proteobacteria}

Soil samples were taken out from $-20^{\circ} \mathrm{C}$ and air dried for 7 days. Then, mortar and pestle were used to grind the samples into smaller particles to increase the efficiency of bacterial isolation. Phenol $\left(1.5 \%, 30 \mathrm{~min}\right.$ at $\left.30^{\circ} \mathrm{C}\right)$ was used for pretreatment of soil samples according to Pisano et al. (1986). The pretreated soil samples were diluted 1:10 (v/v) with sterile $1 / 4$ Ringer solution and serial dilution up to $10^{-4}$. One hundred microliters of the $10^{-1}, 10^{-2}, 10^{-3}$, and $10^{-4}$ suspensions were spread in triplicate onto isolation media.

Dilutions of soil suspensions were spread onto 12 different isolation media, namely ISP media 2-4, 5-7 (Shirling and Gottlieb, 1966), IM2 (Gause modified medium 1; Ivantiskaya et al., 1978), IM3 (rafinose-histidine medium; Williams et al., 1984), SCA (starch casein agar; Küster and Williams, 1964), HVA (humic acid-vitamin agar; Hayakawa and Ohara, 1987), SA (Streptomyces agar; Atlas, 1993), and AIA (Actinomycetes isolation agar; Atlas, 1993). All the media were supplemented with $50 \mathrm{mg} / \mathrm{L}$ cycloheximide, $50 \mathrm{mg} / \mathrm{L}$ nystatin and $20 \mathrm{mg} / \mathrm{L}$ nalidixic acid (Williams and Davies, 1965) and incubated at $28^{\circ} \mathrm{C}$ for $1-4$ weeks. Purified cultures were maintained on ISP medium 2 (Shirling and Gottlieb, 1966) at room temperature and as glycerol suspensions $(20 \%, \mathrm{v} / \mathrm{v})$ at $-20^{\circ} \mathrm{C}$. 


\section{Molecular characterization of proteobacterium species isolates}

\section{DNA extraction from pure cultures and PCR amplification}

Genomic DNA of proteobacteria was extracted as described by Hong et al. (2009). The DNA yield and quality were assessed by $0.8 \%(\mathrm{w} / \mathrm{v})$ agarose gel electrophoresis followed by DNA quantification using a Biophotometer (Eppendorf, Germany). Pure DNA has an $\mathrm{A}_{260} /$ $\mathrm{A}_{280}$ ratio of 1.7-1.9. PCR amplification was performed using the primer pair EuBac27FEubac1492R (Lane, 1991) and an Eppendorf Mastercycler (Eppendorf) was used to run PCR. The PCR mixture consisted of 20-200 ng bacterial genomic DNA, 2.0 $\mu \mathrm{L}$ 10X PCR buffer with $20 \mathrm{mM} \mathrm{MgCl}_{2}, 2.0 \mu \mathrm{L} 10 \mathrm{mM}$ dNTPs, $1 \mathrm{U}$ Taq polymerase (Intron Biotechnology, South Korea), $200 \mathrm{pM}$ of each primer (EuBac27F and Eubac1492R), and sterile ultrapure water was added to a final volume of $20 \mu \mathrm{L}$. The cycling parameters were $5 \mathrm{~min}$ at $95^{\circ} \mathrm{C}$ for predenaturation, 35 cycles each of $50 \mathrm{~s}$ at $95^{\circ} \mathrm{C}$ for denaturation, $60 \mathrm{~s}$ at $52^{\circ} \mathrm{C}$ for annealing, $90 \mathrm{~s}$ at $72^{\circ} \mathrm{C}$ for extension and a final extension of $72^{\circ} \mathrm{C}$ for $10 \mathrm{~min}$. The PCR amplification products were resolved by electrophoresis on 1.5\% agarose gel (Promega, USA), which was stained with ethidium bromide $(0.5 \mu \mathrm{g} / \mathrm{mL})$ and viewed under the Alpha Imager gel documentation system (Alpha Innotech, USA).

\section{Molecular cloning, sequencing and phylogenetic analysis}

PCR products were purified using a GeneAll Expin Gel SV purification kit (GeneAll, South Korea) and ligated to pDrive plasmid vector (Qiagen, Germany) and the ligation products transformed into competent Escherichia coli JM109. The insertion of the gene of interest was verified through blue-white colony selection followed by colony-PCR. Purified plasmid DNA was extracted using the Eppendorf FastPlasmid ${ }^{\mathrm{TM}}$ Mini kit and served as templates for PCR to confirm the insertion of the gene of interest. Plasmid DNA was sequenced with an ABI PRISM $^{\circledR} 3100$ DNA sequencer (Applied Biosystems).

The 16S rRNA gene sequences were aligned manually with sequences from the most closely related genera retrieved from the GenBank/EMBL/DDBJ databases using the CLUSTAL-X software (Thompson et al., 1997). The calculations of level of sequence similarity were performed using EzTaxon server 2.1 (Chun et al., 2007). A phylogenetic tree was inferred using neighbor joining algorithms (Saitou and Nei, 1987) using MEGA version 4.0 (Tamura et al., 2007). The stability of the resultant tree topologies was evaluated by bootstrap analysis (Felsenstein, 1985). Pairwise distances between sequences were generated using Kimura's 2-parameter model (Kimura, 1980).

\section{ERIC-PCR analysis of proteobacteria}

The proteobacterium species isolates were cultured and purified on ISP 2 medium. Genomic DNA was obtained and PCR were carried out as described by Versalovic et al. (1991) using the primer set ERIC-1R (5'-ATGTAAGCTCCTGGGGATTCAC-3') and ERIC-2 (5'-AAGTAAG TGACTGGGGTGAGCG-3'). The cycling parameters were 4 min at $95^{\circ} \mathrm{C}$ for pre-denaturation, 35 cycles each of $1 \mathrm{~min}$ at $94^{\circ} \mathrm{C}$ for denaturation, $1 \mathrm{~min}$ at $52^{\circ} \mathrm{C}$ for annealing, $3 \mathrm{~min}$ at $65^{\circ} \mathrm{C}$ for extension, and a final extension at $65^{\circ} \mathrm{C}$ for $8 \mathrm{~min}$. Negative controls (no added DNA) were in- 
cluded in all sets of reactions. The PCR amplification products were resolved by electrophoresis on $1.5 \%$ agarose gel (Promega), which was stained with $0.5 \mu \mathrm{g} / \mathrm{mL}$ ethidium bromide and viewed under the Alpha Imager gel documentation system (Alpha Innotech). The ERIC-PCR assays were repeated three times to determine the reproducibility of the banding patterns generated. The ERIC-PCR profiles were compared on the basis of the presence or absence of each DNA band and a data matrix was constructed. Strain diversity was calculated using the Dice's coefficient and UPGMA (unweighted pair-group arithmetic average) cluster analysis.

\section{RAPD analysis of proteobacteria}

A total of 6 arbitrary primers (OPO 06, 07, 08,09, 10, and 11) were tested to discriminate representative isolates of proteobacteria. Only one primer, namely OPO 10 (5'-TCAGAGCGCC-3'), was selected for RAPD analysis as it provided reproducible and discriminatory banding patterns. The PCR mixture consisted of 20-200 ng bacterial genomic DNA, $2.0 \mu \mathrm{L}$ 10X PCR buffer with $20 \mathrm{mM} \mathrm{MgCl}_{2}, 2.0 \mu \mathrm{L} 10 \mathrm{mM}$ dNTPs, 1 U Taq polymerase (Intron Biotechnology), $200 \mathrm{pM}$ primer OPO 10, and sterile ultrapure water was added to a final volume of $20 \mu \mathrm{L}$. The cycling parameters were 4 min at $95^{\circ} \mathrm{C}$ for pre-denaturation, 40 cycles each of $1 \mathrm{~min}$ at $94^{\circ} \mathrm{C}$ for denaturation, $1 \mathrm{~min}$ at $36^{\circ} \mathrm{C}$ for annealing, $1 \mathrm{~min}$ at $72^{\circ} \mathrm{C}$ for extension, and a final extension at $72^{\circ} \mathrm{C}$ for $7 \mathrm{~min}$. Negative controls (no added DNA) were included in all sets of reactions. The PCR amplification products were resolved by electrophoresis as mentioned above. RAPD was repeated three times to determine the reproducibility of the banding patterns generated. Strain diversity was calculated using the Dice's coefficient and UPGMA cluster analysis.

\section{Calculation of discrimination indices}

The discriminatory power of each typing method was determined by calculating the discriminatory index using the Simpson's index of diversity, a method described by Hunter and Gaston (1988). The following is the formula for calculating the discrimination index:

$$
\begin{aligned}
& 1 S \\
& D=1---------\sum n_{j}\left(n_{j}-1\right) \\
& N(N-1)_{j=1}
\end{aligned}
$$

where $D$ is a numerical index of discrimination; $N$ is the total of strains in the sample population; $S$ is the total number of types described, and $n_{j}$ is the number of strains belonging to the $j$ th type.

Calculating the discrimination value $\mathrm{D}$ allows comparison of the discriminatory powers of typing methods.

\section{Preparation of crude extracts for secondary metabolite screening}

The fermentation medium used was FM3 (Garcia et al., 1999), FM2 (Yu et al., 2008) and FM17 (Chen et al., 2006). All media were autoclaved at $121^{\circ} \mathrm{C}$ for $20 \mathrm{~min}$. Each of the 57 isolates were transferred to a test tube $(30 \times 200 \mathrm{~mm})$, which contained $20 \mathrm{~mL}$ of the relevant fermentation medium, and cultured at $200 \mathrm{rpm}$, at an angle of $45^{\circ}$, for $7-10$ days at $28^{\circ} \mathrm{C}$. 


\section{Screening for antimicrobial metabolites}

The method used for screening of antimicrobial metabolites was modified from Hong and Xiao (2006). Candida albicans ATCC $10231^{\mathrm{T}}$ was cultured overnight at $30^{\circ} \mathrm{C}$ at $200 \mathrm{rpm}$ in YPD medium ( $2 \%$ glucose; $2 \%$ tryptone; $1 \%$ yeast extract; $\mathrm{pH} 5.0 \sim 5.5)$ whereas Staphylococcus aureus ATCC $51650^{\mathrm{T}}$, methicillin-resistant $S$. aureus (MRSA) ATCC BAA-44 ${ }^{\mathrm{T}}$ and Pseudomonas aeruginosa ATCC $10145^{\mathrm{T}}$ were cultured overnight at $37^{\circ} \mathrm{C}$ and at $200 \mathrm{rpm}$ in nutrient broth. The resultant cultures were diluted with their respective media to $0.8-1.2 \mathrm{x}$ $10^{6} \mathrm{CFU} / \mathrm{mL}$, and $100 \mu \mathrm{L}$ aliquots of this inoculum were transferred to individual wells in a 96-well plate. An aliquot of 1-mL culture fermentation broth (FM3, FM2, FM17) from each isolates was centrifuged at $10,000 \mathrm{rpm}$ and at $4^{\circ} \mathrm{C}$. The fermentation broth supernatant $(100$ $\mu \mathrm{L}$ ) was taken from each of the isolates and added to each of the wells. The two culture media were used as negative controls, and fluconazole as the positive controls for the anti-C. albicans while cefoperazone/tazobactom were used as the positive controls for anti-S. aureus, antiMRSA and anti-P. aeruginosa assays. The 96-well plates were shaken at $200 \mathrm{rpm}$ for $24 \mathrm{~h}$ at $37^{\circ} \mathrm{C}$ for all assays except for anti-C. albicans assay that was shaken at $30^{\circ} \mathrm{C}$. After incubation, all plates were assayed with a microplate spectrophotometer (Multiskan Mk3, Finland) at 570 $\mathrm{nm}$. The absorbance readings from each well were used to record bioactivities as "+", “++", or " +++ " for higher or equal to $4-6,6-8$ and $8 \mu \mathrm{g} / \mathrm{mL}$ of standard, respectively. Serial dilutions of the antibiotics $(128,64,32,16,14,12,10,8,6,4,2$, and $1 \mu \mathrm{g} / \mathrm{mL})$ were used to generate standard curves.

\section{RESULTS}

\section{Isolation and identification of proteobacteria}

A total of 57 proteobacterium apecies isolates were successfully isolated from 3 soil samples collected from Barrientos Island. Soil samples labeled 445, 446 and 453 contributed to 19,12 and $68 \%$, respectively, to the total number of isolates. Isolates were identified using PCR and sequencing of 16S rRNA gene sequences. Fifty-seven isolates belonged to 8 different genera in phylum proteobacteria, namely genera Bradyrhizobium, Sphingomonas, Methylobacterium, Caulobacter, Paracoccus, Ralstonia, Rhizobium, and Staphylococcus with 27, $16,9,1,1,1,1$, and 1 isolates, respectively. From a total of 12 types of isolation media used, 11 isolation media successfully isolated proteobacteria, namely media SCA, AIA, HVA, ISP 3, SA, IM2, ISP 7, rafinose-histidine agar, ISP 4, ISP 6, and ISP 2 with 11, 7, 7, 7, 7, 5, 5, 3, 2, 2 , and 1 isolates, respectively. This result indicated that SCA was the most suitable medium to isolate proteobacteria from Barrientos Island.

\section{Taxonomy diversity of bioactive proteobacteria}

The antimicrobial capability of secondary metabolites of 57 proteobacterium apecies isolates were determined using 4 high throughput screening models, namely against $C$. albicans ATCC $10231^{\mathrm{T}}$, S. aureus ATCC $51650^{\mathrm{T}}$, MRSA ATCC BAA- $44^{\mathrm{T}}$, and P. aeruginosa ATCC $10145^{\mathrm{T}}$. After the screening, a total of 14 isolates produced bioactive metabolites and proceeded to cloning and sequencing of the $16 \mathrm{~S}$ rRNA gene sequence. Bioactive proteobacte- 
rium isolates were classified into 4 genera in 4 families (Table 1). The genera Bradyrhizobium, Paracoccus and Sphingomonas contributed 9, 1 and 1 isolates active against the pathogen $C$. albicans. While 3 isolates from the genus Methylobacterium showed bioactivity against $S$. aureus (1 isolate) and C. albicans (2 isolates). None of the isolates of proteobacteria showed any bioactivity against $P$. aeruginosa or MRSA (Table 1 ).

Table 1. Identification of different antimicrobial secondary metabolites from proteobacteria isolated from soils of Barrientos Island, Antarctic.

\begin{tabular}{lllcccc}
\hline Phylum & Genera & Families & \multicolumn{3}{c}{ Number of identified representative strains } \\
\cline { 3 - 6 } & & Anti-S. aureus & Anti-MRSA & Anti-C. albicans & Anti-P. aeruginosa \\
\hline Proteobacteria & Bradyrhizobium & Bradyrhizobiaceae & 0 & 0 & 9 & 0 \\
& Methylobacterium & Methylobacteriaceae & 1 & 0 & 2 & 0 \\
& Paracoccus & Rhodobacteraceae & 0 & 0 & 1 & 0 \\
& Sphingomonas & Sphingomonadaceae & 0 & 0 & 1 & 0 \\
\hline
\end{tabular}

\section{Sequence alignment and phylogenetic analysis of bioactive proteobacteria}

Analysis of the 16S rRNA gene sequences were performed using the Basic Local Alignment Search Tool (BLAST) under EzTaxon server 2.1 (Chun et al., 2007). The 16S rRNA sequences of type strains were retrieved from DDBJ/EMBL/GenBank databases and aligned with isolate sequences obtained in this study. Sequence alignment showed that 8 isolates (BR42, BR62, BR65, BR82, BR88, BR96, BR100, and BR105) belonged to a member of the genus Bradyrhizobium with $99.3-99.7 \%$ identity to B. pachyrhizi PAC48 ${ }^{\mathrm{T}}$ (Table 2). Only 1 isolate (BR45) exhibited $99.2 \%$ similarity to $B$. lablabi CCBAU $23086^{\mathrm{T}}$. The sequences of isolates MB63 and MB104 exhibited 100 and 99.7\% similarity to Methylobacterium jeotgali S2R03-9 ${ }^{\mathrm{T}}$ while isolate MB20 demonstrated $98.7 \%$ identity to M. platani PMB02 ${ }^{\mathrm{T}}$. The sequences of isolates PC101 and SM14 demonstrated 97.1 and $99.9 \%$ identity to sequences of type strain Paracoccus chinensis KS-11 ${ }^{\mathrm{T}}$ and Sphingomonas melonis DAPP-PG $224^{\mathrm{T}}$, respectively. Proteobacteria that exhibited high taxonomical diversity were those that demonstrated activity against $C$. albicans. A total of 13 isolates from 4 different genera were positive in producing secondary metabolites against $C$. albicans (Table 1 ).

\begin{tabular}{|c|c|c|c|}
\hline Isolate number & Closest relative & Accession No. & Sequence identity (\%) \\
\hline BR45 & Bradyrhizobium lablabi CCBAU $23086^{\mathrm{T}}$ & GU433448 & 99.2 \\
\hline BR42 & Bradyrhizobium pachyrhizi $\mathrm{PAC} 48^{\mathrm{T}}$ & AY624135 & 99.6 \\
\hline BR62 & Bradyrhizobium pachyrhizi $\mathrm{PAC} 48^{\mathrm{T}}$ & AY624135 & 99.7 \\
\hline BR65 & Bradyrhizobium pachyrhizi $\mathrm{PAC} 48^{\mathrm{T}}$ & AY624135 & 99.7 \\
\hline BR82 & Bradyrhizobium pachyrhizi $\mathrm{PAC} 48^{\mathrm{T}}$ & AY624135 & 99.5 \\
\hline BR88 & Bradyrhizobium pachyrhizi $\mathrm{PAC} 48^{\mathrm{T}}$ & AY624135 & 99.7 \\
\hline BR96 & Bradyrhizobium pachyrhizi $\mathrm{PAC} 48^{\mathrm{T}}$ & AY624135 & 99.7 \\
\hline BR100 & Bradyrhizobium pachyrhizi $\mathrm{PAC} 48^{\mathrm{T}}$ & AY624135 & 99.7 \\
\hline BR105 & Bradyrhizobium pachyrhizi $\mathrm{PAC} 48^{\mathrm{T}}$ & AY624135 & 99.3 \\
\hline MB63 & Methylobacterium jeotgali $\mathrm{S} 2 \mathrm{R} 03-9^{\mathrm{T}}$ & DQ471331 & 100.0 \\
\hline MB104 & Methylobacterium jeotgali S2R03-9 $9^{\mathrm{T}}$ & DQ471331 & 99.7 \\
\hline MB20 & Methylobacterium platani $\mathrm{PMB} 2^{\mathrm{T}}$ & EF426729 & 98.7 \\
\hline PC101 & Paracoccus chinensis $\mathrm{KS}-11^{\mathrm{T}}$ & EU660389 & 97.1 \\
\hline SM14 & Sphingomonas melonis DAPP-PG $224^{\mathrm{T}}$ & AB055863 & 99.9 \\
\hline
\end{tabular}


The phylogenetic tree of the 16S rRNA gene sequence (Figure 1) signified that isolates BR42, BR45, BR62, BR65, BR82, BR88, BR96, BR100, and BR105 were grouped in the Bradyrhizobium clade together with type strain B. lablabi CCBAU $23086^{\mathrm{T}}$, B. pachyrhizi $\mathrm{PAC} 48^{\mathrm{T}}$ and $B$. jicamae PAC $68^{\mathrm{T}}$ supported by a high bootstrap value of $100 \%$ (Figure 1). Isolate MB20 formed a distinct clade with type strain M. platani $\mathrm{PMB} 02^{\mathrm{T}}$ supported by a bootstrap of $70 \%$, while isolate MB63 and MB104 clustered with type strain M. jeotgali S2R03-9 and formed a subclade with $100 \%$ bootstrap support. The positions of the Paracoccus clade exhibited that isolate PC101 grouped with P. chinensis $\mathrm{KS}-11^{\mathrm{T}}$ at a low bootstrap value of $38 \%$, while isolate SM14 clustered together with S. melonis DAPP-PG $224^{\mathrm{T}}$ with bootstrap support of $99 \%$. All the bioactive proteobacteria from the different genera (Bradyrhizobium, Methylobacterium, Paracoccus, and Sphingomonas) formed relatively distinct phyletic lines with their respective type strain from the same genera.

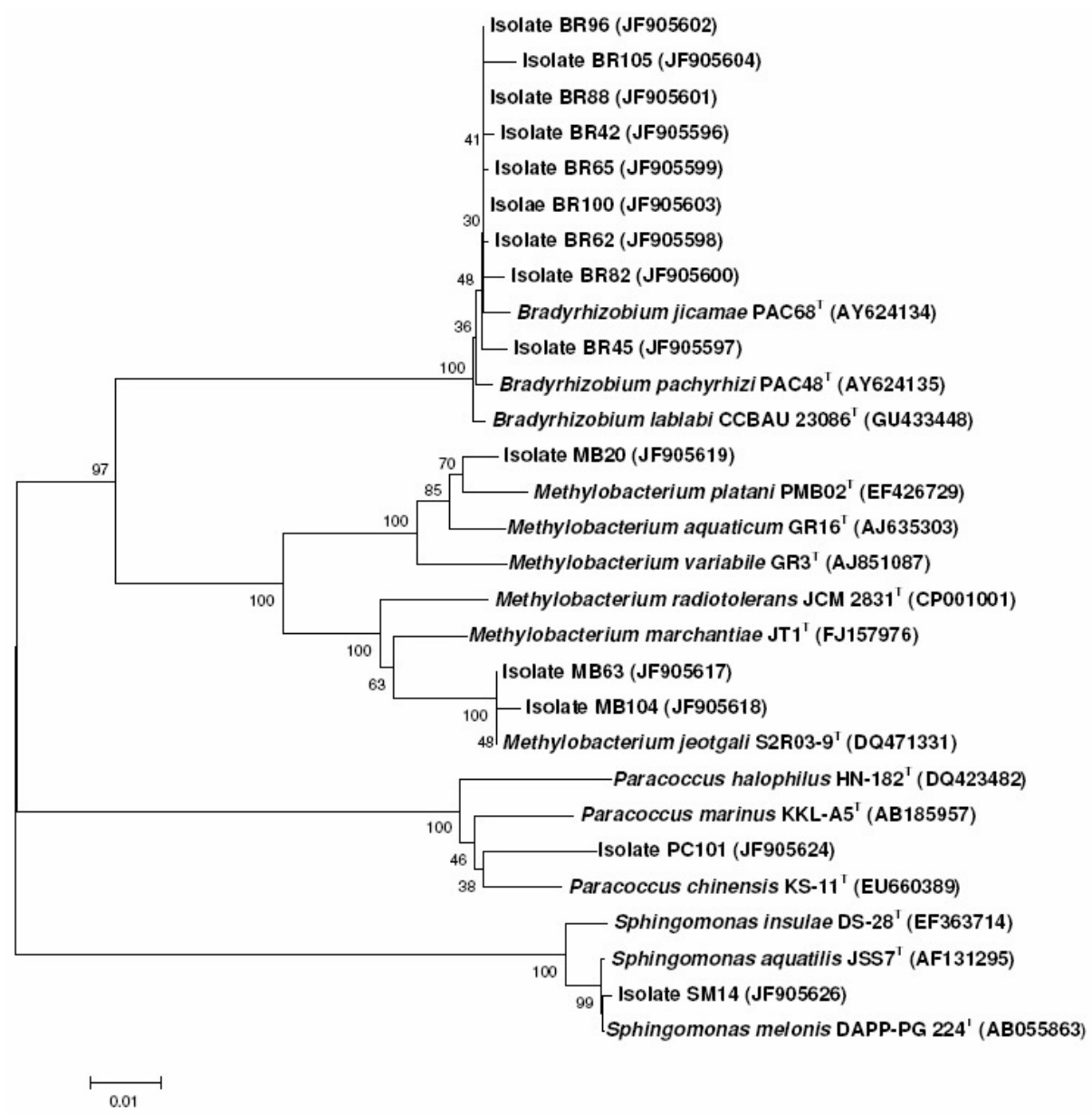

Figure 1. Neighbor-joining tree based on almost complete 16S rRNA gene sequences showing relationships between 14 bioactive isolates of proteobacteria and between them the type strains of the highest 16S rRNA sequence similarity. Numbers at nodes indicate bootstrap values based on 1000 replicates. Bar $=1 \%$ sequence divergence. 


\section{ERIC-PCR analysis of proteobacteria}

ERIC-PCR fingerprinting of a total of 57 isolates exhibited specific patterns corresponding to particular genotypes with amplified bands ranging in size from $<250$ to $10,000 \mathrm{bp}$. A dendrogram (Figure 2) generated from ERIC-PCR analysis demonstrated high discriminatory capability by producing genus-specific clusters that were able to discriminate all of the different genera in this study. A total of 57 proteobacterium species isolates were grouped into 9 clusters (A, H, I, J, K, O, P, Q, and T) and 13 single isolates (B, C, D, E, F, G, L, M, N, R, $\mathrm{S}, \mathrm{U}$, and $\mathrm{V}$ ) at a similarity level of $65 \%$ with a high D value of 0.9248 (Figure 2). ERIC-PCR demonstrated good discriminatory capability as all the clusters formed ( 9 clusters) comprised a single type of genus only (Figure 2).

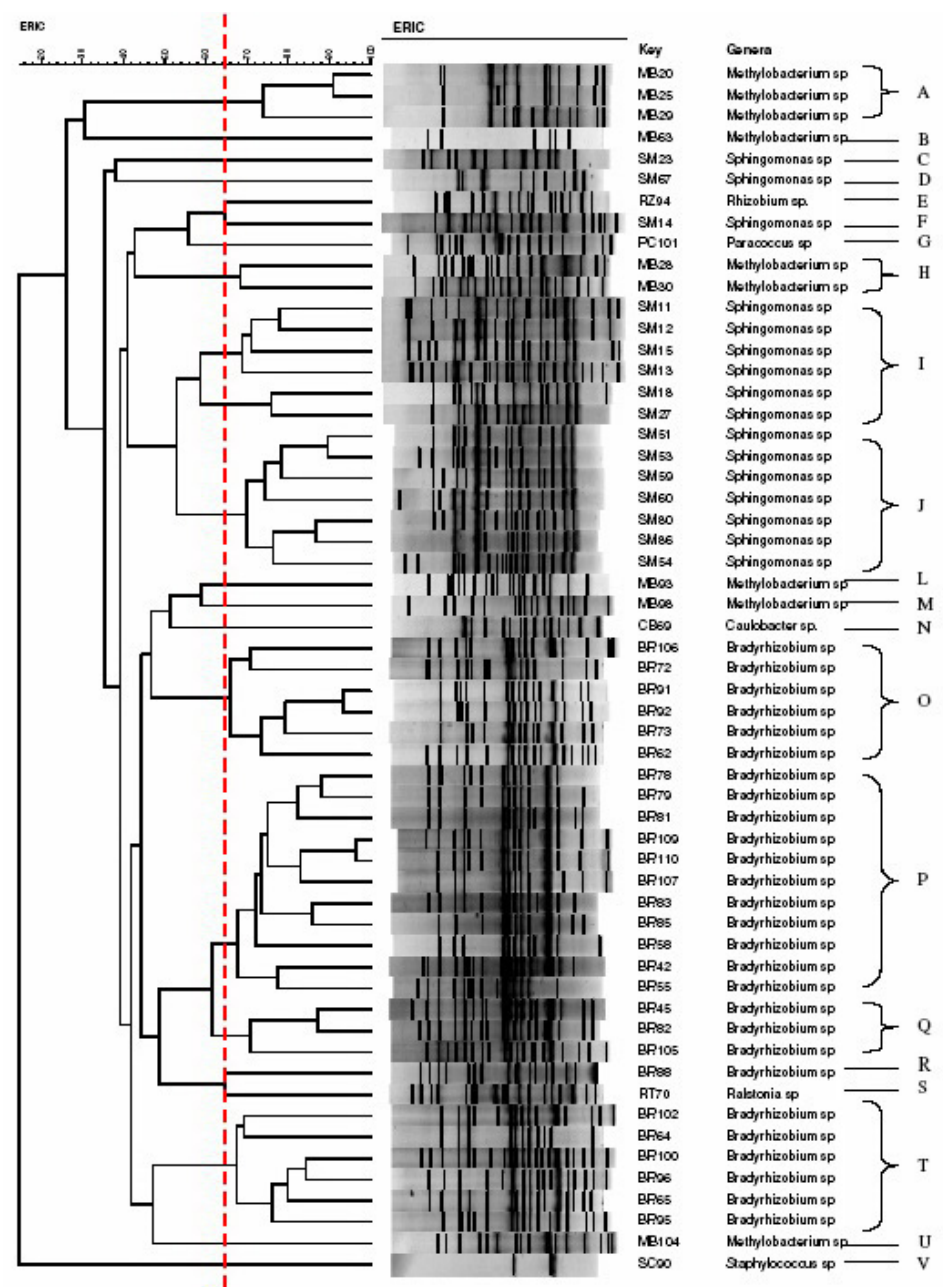

Figure 2. Dendrogram generated from enterobacterial repetitive intergenic consensus (ERIC)-PCR fingerprinting of 57 isolates of proteobacteria. A total of 9 clusters $(\mathrm{A}, \mathrm{H}, \mathrm{I}, \mathrm{J}, \mathrm{K}, \mathrm{O}, \mathrm{P}, \mathrm{Q}$, and T) and 13 single isolates $(\mathrm{B}, \mathrm{C}, \mathrm{D}, \mathrm{E}$, F, G, L, M, N, R, S, U, and V) were observed at similarity level of $65 \%$. 
The dendrogram in Figure 3 was derived from ERIC-PCR analysis of 14 bioactive proteobacteria. This dendrogram comprised 4 main clusters. The first and second clusters were isolates MB63 and MB20 from genera of Methylobacterium. The third cluster consisted of isolate MB104 (Methylobacterium), SM14 (Sphingomonas) and PC101 (Paracoccus). The fourth cluster comprised 9 isolates (BR42, BR88, BR45, BR82, BR105, BR100, BR96, BR65, and BR62) from the genus Bradyrhizobium.

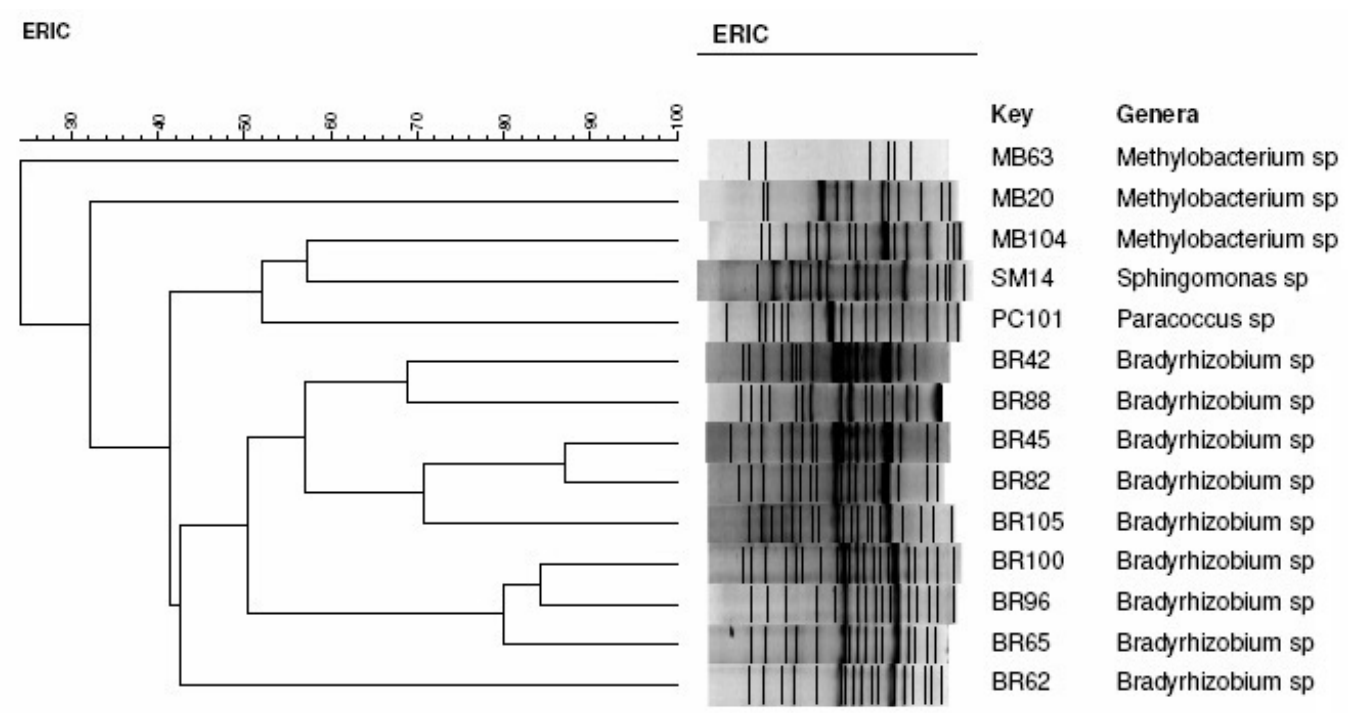

Figure 3. Dendrogram generated from enterobacterial repetitive intergenic consensus (ERIC)-PCR fingerprinting of 14 isolates of bioactive proteobacteria.

\section{RAPD analysis of proteobacteria}

RAPD results from arbitrary primer OPO 10 showed specific patterns corresponding to particular genotypes with amplified DNA fragments ranging from $<250$ to $10,000 \mathrm{bp}$. Figure 4 shows a dendrogram generated from the analysis of 57 proteobacterium species isolates and exhibited low discriminatory capability by producing 6 clusters $(\mathrm{d}, \mathrm{e}, \mathrm{h}, \mathrm{i}, \mathrm{j}, \mathrm{o})$ and 13 single isolates ( $a, b, c, f, g, k, 1, m, n, p, q, r, s)$ with a $D$ value of 0.7776 at a similarity level of $65 \%$. From the 6 clusters formed, 5 clusters $(\mathrm{d}, \mathrm{h}, \mathrm{i}, \mathrm{j}, \mathrm{o})$ comprised a single genus only, whereas cluster 'e' comprised isolates from 2 different genera, namely Ralstonia and Rhizobium.

RAPD pattern analysis of 14 bioactive proteobacterium species isolates was performed and is illustrated in Figure 5. This dendrogram comprised 5 main clusters. The first cluster comprised 8 isolates from the genus Bradyrhizobium, namely BR105, BR45, BR42, BR65, BR82, BR96, BR100, and BR62. Isolates BR88 (Bradyrhizobium) and MB104 (Methylobacterium) formed the second cluster. The third cluster consisted of the single isolate MB63 from the genus Methylobacterium while the fourth cluster contained isolate MB20 and SM14 from genera Methylobacterium and Sphingomonas. The last cluster comprised 1 isolate (PC101) from the genus Paracoccus. 


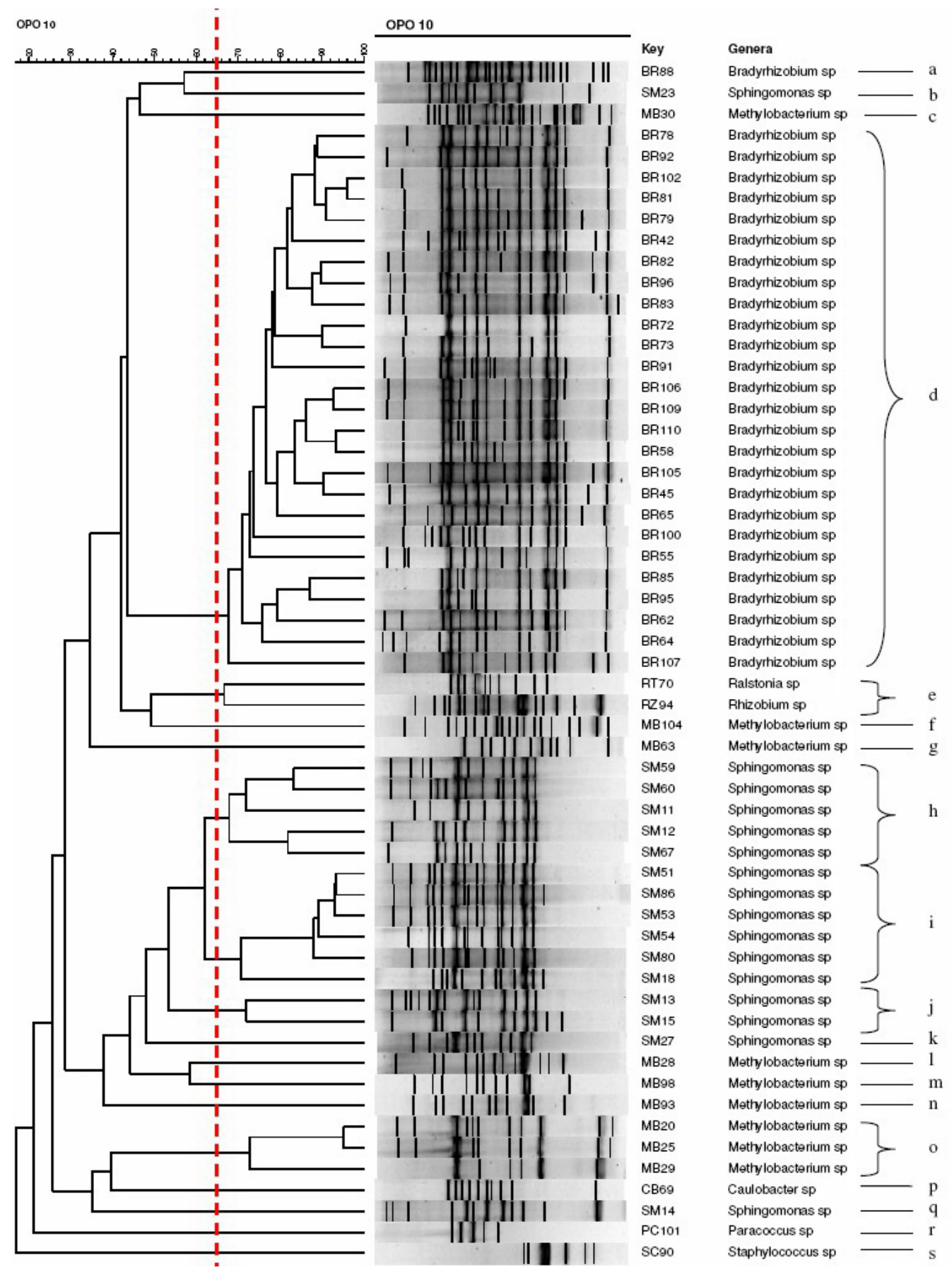

Figure 4. Dendrogram generated from RAPD fingerprinting of 57 isolates of proteobacteria. A total of 6 clusters $(\mathrm{d}, \mathrm{e}, \mathrm{h}, \mathrm{i}, \mathrm{j}, \mathrm{o})$ and 13 single isolates $(\mathrm{a}, \mathrm{b}, \mathrm{c}, \mathrm{f}, \mathrm{g}, \mathrm{k}, \mathrm{l}, \mathrm{m}, \mathrm{n}, \mathrm{p}, \mathrm{q}, \mathrm{r}, \mathrm{s})$ were observed at a similarity level of $65 \%$. 


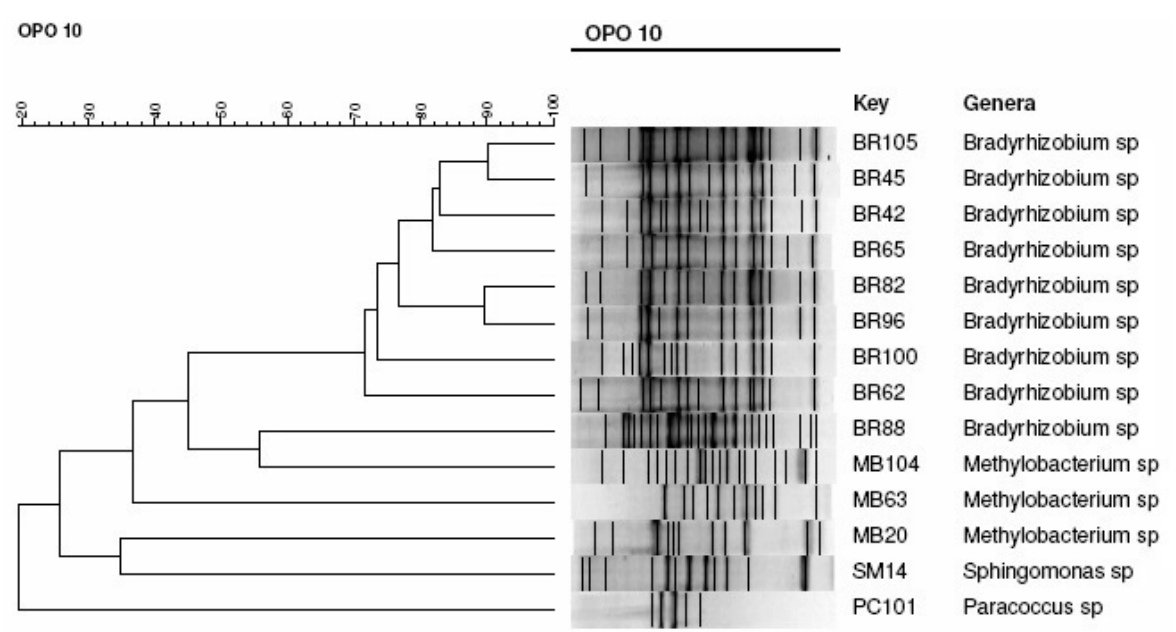

Figure 5. Dendrogram generated from RAPD fingerprinting of 14 isolates of bioactive proteobacteria.

\section{DISCUSSION}

Lately, due to frequent genetic exchange between species of bacteria, the chances of discovering new bioactive compounds from bacteria are low. This phenomenon has resulted in similar or identical finding of compounds from well-known bacteria even though they were isolated from different environments (Bredholt et al., 2008). The reduction of new metabolites discovered has forced the search into new habitats. Poorly explored areas or unusual environments have become critical for the discovery of novel compounds and bacteria (Saadoun and Gharaibeh, 2003; Lam, 2007; Newman and Cragg, 2007; Thakur et al., 2007). Therefore, soil samples taken from the Antarctic, one of the coldest and most poorly explored regions of the world, present good potential for the discovery of novel bioactive metabolites and compounds from microorganisms like bacteria (Marinelli et al., 2004; Tindall, 2004; Taton et al., 2006).

This study was conducted to investigate the diversity and antimicrobial bioactivity of proteobacteria by performing isolation, molecular identification, molecular characterization, and bioactive secondary metabolite screening using 4 high-throughput screening models. A total of 57 isolates of proteobacteria were successfully isolated from 11 different media and they belonged to 8 different genera. Soil sample ' 453 ' exhibited the highest diversity and density of the proteobacterium population among all soil samples used in this study, with $68 \%$ (39/57) of isolates from 8 different genera of proteobacteria successfully isolated from this soil sample. The wide spread of various genera of proteobacteria in the Antarctic showed that their distribution is highly endemic, especially in soil. This observation is in agreement with Aislabie et al. (2008), which reported that the diversity of bacteria, including proteobacteria, in the Ross Sea region of the Antarctic is highly widespread. This information will benefit the bio-prospecting of bacteria from sampling soil from the Antarctic region.

A total of $25 \%(14 / 57)$ of proteobacterium species isolates belonged to 4 genera (Bradyrhizobium, Methylobacterium, Sphingomonas, and Paracoccus) and 4 families exhibited antimicrobial properties. Four genera (Caulobacter, Rhizobium, Ralstonia, and Staphy- 
lococcus) did not exhibit any bioactivity against 4 different screening models used. From the 4 screening models used, 2 obtained positive results with 13 isolates $(23 \%)$ active against $C$. albicans and 1 isolate (2\%) against $S$. aureus. The most bioactive genus was Bradyrhizobium, which contributed with 9 bioactive isolates or $64 \%(9 / 14)$ of the total bioactive isolates in this study. This showed that the production of antibiotics or toxins from Antarctic bacteria could be a mechanism to confer them a competitive survival capability (Vincent, 2000).

Recently, more global findings have shown that novel bacteria from various extreme or poorly explored environments are capable of producing valuable sources of new bioactive metabolites and compounds (Bredholt et al., 2008; Rojas et al., 2009). Therefore, it is important to determine the taxonomic relationships and metabolic diversity of bacteria. In this study, 16S rRNA sequence analysis showed that 1 bioactive isolate (PC101) was highly likely to be assigned to new species as they are separated from their respective type strains of phylogenetic neighbors by sequence similarities well below those found between closely related species in the same genera. The $16 \mathrm{~S}$ rDNA sequence similarity of PC101 to the type strain P. chinensis KS-11 was lower than $97.1 \%$ (Table 2). This value is low as compared to the similarity of type strain P. chinensis KS-11 to its closest related species P. niistensis NII-0918, which was as high as $99.1 \%$ (data not shown). The irregular combination of selection pressures could lead to evolution that produces novel chemical adaptation and formation of novel strains (Ellis-Evans and Walton, 1990; Vincent, 2000).

PCR fingerprinting methods like ERIC-PCR and RAPD were used to study the relatedness between proteobacterium species isolates from different genera. ERIC-PCR uses oligonucleotides targeting short repetitive sequences dispersed throughout various bacterial genomes. ERIC sequences are dispersed throughout the genome of enterobacteriaceae in different orientations thus enabling their location in bacterial genomes, which allows discrimination at genus and species level based on their electrophoretic amplification DNA fragments (Yoke-Kqueen et al., 2008; Nimnoi et al., 2010). The ERIC-PCR pattern obtained in this study showed good resolution and generated a high discriminatory pattern with $100 \%$ (9/9) genus-specific clusters that deciphered isolates of different genera from each other completely. The D value of ERIC-PCR fingerprinting was the highest in this study, with 0.9248 at a $65 \%$ similarity level (Figure 2).

RAPD analysis has achieved excellent results for genomic typing of various microorganisms (de Oliveira et al., 2002; Learn-Han et al., 2008; Nimnoi et al., 2010). Therefore, arbitrary primer OPO 10 was used to fingerprint proteobacterium species isolates in this study. However, our results indicated that RAPD exhibited rather weak discriminatory capability as compared to ERIC-PCR. RAPD analysis produced 83\% (5/6) genus-specific cluster with a low $\mathrm{D}$ value of 0.7776 at a similarity level of $65 \%$ (Figure 4 ). This result is significantly lower compared to ERIC-PCR, thus demonstrating that ERIC-PCR is much more discriminatory than RAPD for fingerprinting of Antarctic proteobacteria in this study.

The consistencies and differences of 14 bioactive proteobacterium species isolates were evaluated using 3 molecular-based techniques including 16S rRNA analysis (Figure 1), ERICPCR (Figure 3) and RAPD (Figure 5). Cluster 3 in the ERIC-PCR dendrogram (Figure 3) consists of isolates from the genera Methylobacterium (MB104), Sphingomonas (SM14) and Paracoccus (PC101) that are also located at the neighboring location in the genetic evolutions 16S rRNA tree (Figure 1). However, this result was different in the RAPD dendrogram (Figure 5) as the position of isolate PC101 was placed in a different position from the others. Many isolates in the fourth cluster generated by the ERIC-PCR pattern were consistent with $16 \mathrm{~S}$ rRNA tree analysis. In this 
cluster (Figure 3), the position of BR42 with BR88, BR45 with BR82, and BR100 with BR62 were closely grouped together and formed a subclade within this cluster. This observation was similar in the 16S rRNA tree that revealed that these different sets of isolates were closely clade together as well (Figure 1). However, RAPD analysis in Figure 5 generated different results with no similar clade formed as compared to ERIC-PCR and 16S rRNA tree analysis.

In conclusion, this study demonstrated that proteobacteria have been successfully isolated from the soils of Barrientos Island using a culturable method and that they are widely distributed. The screening for bioactive secondary metabolites showed that $25 \%$ of proteobacterium species isolates were highly bioactive. These results indicate that proteobacterium species isolates from the Antarctic could serve as a potential source of useful bioactive metabolites for various antimicrobial screening models. Molecular characterization methods like analysis of 16S rRNA sequences is a powerful tool in determining higher taxonomic relationships of proteobacteria. ERIC-PCR analysis showed better discriminatory capability than RAPD with the best clustering and highest $\mathrm{D}$ value of 0.9248 . Therefore, in this study ERIC-PCR was a robust, reliable and rapid molecular typing method in discriminating different proteobacterium species isolates.

\section{ACKNOWLEDGMENTS}

The authors are grateful to Instituto Antártico Ecuatoriano (INAE) for their support during the XI Ecuadorian Antarctic Expedition to "Pedro Vicente Maldonado" Research Station, Greenwich Island, South Shetlands Islands. The authors are thankful to Gao Zhu-Fen and Li Xiao-Hui for laboratory assistance. Research supported by the Malaysia Antarctic Research Program, Academy of Sciences Malaysia and the Universiti Putra Malaysia Research Universiti Grant Scheme (\#05-01-11-1219RU).

\section{REFERENCES}

Aislabie JM, Jordan S and Barker GM (2008). Relation between soil classification and bacterial diversity in soils of the Ross Sea region, Antarctica. Geoderma 144: 9-20.

Atlas RM (1993). Handbook of Microbiological Media (Parks L, ed.). CRC Press, Boca Raton.

Bredholt H, Fjaervik E, Johnsen G and Zotchev SB (2008). Actinomycetes from sediments in the Trondheim fjord, Norway: diversity and biological activity. Mar. Drugs 6: 12-24.

Bull AT and Stach JE (2007). Marine actinobacteria: new opportunities for natural product search and discovery. Trends Microbiol. 15: 491-499.

Chen H, Hong K, Zhuang L and Zhong QP (2006). Growth characteristics and fermentation condition optimization of mangrove actinomycete strain 0616167. Microbiology 33: 16-20.

Chun J, Lee JH, Jung Y, Kim M, et al. (2007). EzTaxon: a web-based tool for the identification of prokaryotes based on 16S ribosomal RNA gene sequences. Int. J. Syst. Evol. Microbiol. 57: 2259-2261.

de Oliveira AM, Matsumura AT, Prestes AM and Van Der Sand ST (2002). Intraspecific variability of Bipolaris sorokiniana isolates determined by random-amplified polymorphic DNA (RAPD). Genet. Mol. Res. 1: 350-358.

Dias de Oliveira S, Siqueira FF, dos Santos LR and Brandelli A (2005). Antimicrobial resistance in Salmonella enteritidis strains isolated from broiler carcasses, food, human and poultry-related samples. Int. J. Food Microbiol. 97: 297-305.

Ellis-Evans JC and Walton D (1990). The process of colonization in Antarctic terrestrial and freshwater ecosystems. Proc. NIPR Symp. Polar Biol. 3: 151-163.

Felsenstein J (1985). Confidence limits on phylogenies: an approach using the bootstrap. Evolution 39: 789.

Garcia GD, Romero MF, Perez BJ and Garcia DT (1999). Thiodepsipeptide isolated from a marine actinomycete WO9527730. Patent No.: US5681813.

Hayakawa M and Nonomura H (1987). Humic acid-vitamin agar, a new medium for the selective isolation of soil actinomycetes. J. Ferment. Technol. 65: 501-509. 
Hong K and Xiao C (2006). A rapid method for detection of biological activity of anti- yeast-like pathogen. China Patent ZL03128096.

Hong K, Gao AH, Xie QY, Gao H, et al. (2009). Actinomycetes for marine drug discovery isolated from mangrove soils and plants in China. Mar. Drugs 7: 24-44.

Hunter PR and Gaston MA (1988). Numerical index of the discriminatory ability of typing systems: an application of Simpson's index of diversity. J. Clin. Microbiol. 26: 2465-2466.

Ivantiskaya LP, Singal SM, Bibikova MV and Vostrov SN (1978). Direct isolation of Micromonospora on selective media with gentamicin. Antibiotiki 23: 690-692.

Kimura M (1980). A simple method for estimating evolutionary rates of base substitutions through comparative studies of nucleotide sequences. J. Mol. Evol. 16: 111-120.

Küster E and Williams ST (1964). Media for the isolation of Streptomycetes: starch casein medium. Nature 202: 928-929.

Lam KS (2007). New aspects of natural products in drug discovery. Trends Microbiol. 15: 279-289.

Lane DJ (1991). 16S/23S rRNA Sequencing. In: Nucleic Acid Techniques in Bacterial Systemic (Stackebrandt E and Goodfellow, eds). Wiley, Chichester, 115-175.

Learn-Han L, Yoke-Kqueen C, Salleh NA, Sukardi S, et al. (2008). Analysis of Salmonella Agona and Salmonella Weltevreden in Malaysia by PCR fingerprinting and antibiotic resistance profiling. Antonie Van Leeuwenhoek 94: 377-387.

Marinelli F, Brunati M, Sponga F, Ciciliato I et al. (2004). Biotechnological Exploitation of Heterotrophic Bacteria and Filamentous Fungi Isolated from Benthic Mats of Antarctic Lakes. In: Microbial Genetic Resources and Biodiscovery (Kurtböke I and Swings J, eds.). Queensland Complete Printing Services, Queensland, 163-184.

Moncheva P, Tishkov S, Dimitrova N, Chipeva V, et al. (2002). Characteristics of soil actinomycetes from Antarctica. $J$. Cult. Collect. 3: 3-14.

Newman DJ and Cragg GM (2007). Natural products as sources of new drugs over the last 25 years. J. Nat. Prod. 70: 461-477.

Nimnoi P, Pongsilp N and Lumyong S (2010). Endophytic actinomycetes isolated from Aquilaria crassna Pierre ex Lec and screening of plant growth promoters production. World J. Microbiol. Biotechnol. 26: 193-203.

Pisano MA, Sommer MJ and Lopez MM (1986). Application of pretreatments for the isolation of bioactive actinomycetes from marine sediments. Appl. Microbiol. Biotechnol. 25: 285-288.

Rojas JL, Martín J, Tormo JR, Vicente F, et al. (2009). Bacterial diversity from benthic mats of Antarctic lakes as a source of new bioactive metabolites. Mar. Genomics 2: 33-41.

Saadoun I and Gharaibeh R (2003). The Streptomyces flora of Badia region of Jordan and its potential as a source of antibiotic resistant bacteria. J. Arid Environ. 53: 365-371.

Saitou N and Nei M (1987). The neighbor-joining method: a new method for reconstructing phylogenetic trees. Mol. Biol. Evol. 4: 406-425.

Shirling EB and Gottlieb D (1966). Methods for characterization of Streptomyces species. Int. J. Syst. Bacteriol. 16: 313-340.

Tamura K, Dudley J, Nei M and Kumar S (2007). MEGA4: Molecular Evolutionary Genetics Analysis (MEGA) software version 4.0. Mol. Biol. Evol. 24: 1596-1599.

Taton A, Grubisic S, Ertz D, Hodgson DA, et al. (2006). Polyphasic study of Antarctic cyanobacterial strains. J. Phycol. 42: $1257-1270$

Thakur D, Yadav A, Gogoi BK and Bora TC (2007). Isolation and screening of Streptomyces in soil of protected forest areas from the states of Assam and Tripura, India, for antimicrobial metabolites. J. Mycol. Med. 17: 242-249.

Thompson JD, Gibson TJ, Plewniak F, Jeanmougin F, et al. (1997). The CLUSTAL_X windows interface: flexible strategies for multiple sequence alignment aided by quality analysis tools. Nucleic Acids Res. 25: 4876-4882.

Tindall BJ (2004). Prokaryotic diversity in the Antarctic: the tip of the iceberg. Microb. Ecol. 47: 271-283.

Versalovic J, Koeuth T and Lupski JR (1991). Distribution of repetitive DNA sequences in eubacteria and application to fingerprinting of bacterial genomes. Nucleic Acids Res. 19: 6823-6831.

Vincent WF (2000). Evolutionary origins of Antarctic microbiota: invasion, selection and endemism. Antarct. Sci. 12: 374-385.

Williams ST and Davies FL (1965). Use of Antibiotics for Selective Isolation and Enumeration of Actinomycetes in Soil. J. Gen. Microbiol. 38: 251-261.

Williams ST, Lanning S and Wellington EMH (1984). Ecology of Actinomycetes. In: The Biology of the Actinomycetes (Goodfellow M, Mordarski M and Williams ST, eds.). Academic Press, London, 481-528.

Yoke-Kqueen C, Noorzaleha AS, Learn-Han L, Son R, et al. (2008). Comparison of PCR fingerprinting techniques for the discrimination of Salmonella enterica subsp. enterica serovar Weltevreden isolated from indigenous vegetables in Malaysia. World J. Microbiol. Biotechnol. 24: 327-335.

Yu JS, Hong K, Lin HP and Yuan GJ (2008). Optimization study on fermentative medium for precursor of daptomycin A21978C produced by Streptomyces roseosporus NRRL 11397. J. Anhui Agric. Sci. 36: 7974-7976. 